\title{
Art, Value, and Function
}

\author{
Severin Schroeder
}

\begin{abstract}
A B STRACT Is the concept of a work of art an evaluative concept: does its application imply a positive evaluation? I shall discuss this question by considering two opposing attempts at defining art, namely the Institutional Theory and the view that art is a functional concept. I shall argue that the concept of art does not imply an unconditionally positive evaluation, but that art is a prestige concept. Moreover, it will be shown that functional definitions of art are flawed.

KEYWORDS The concept of art, institutional theory of art, functional definition of art
\end{abstract}

I

The key idea of George Dickie's Institutional Theory of Art is that in the light of the subversive excesses of avant-garde art any attempt to define art in terms of its form or content is doomed to failure. Dadaism, Duchamp's Fountain and John Cage's 4'33" have demonstrated that virtually anything can become art. What makes the difference between art and non-art (e.g. Fountain and an ordinary urinal) are no intrinsic features of the objects in question, but people's attitudes. It all depends on whether an object is assigned a certain position within an established social practice. According to the first version of the Institutional Theory (1974), this position or status is conferred upon an object by some person acting on behalf of the artworld. Thus, art is produced by a kind of proclamation. In a later version of the theory (1984), Dickie replaced the idea of a conferral by that of a suitable presentation. This is his revised definition:

(IT) A work of art in the classificatory sense is an artifact of a kind created to be presented to an artworld public. ${ }^{1}$

Presentation to a suitable audience is the paradigmatic procedure by which art is typically made, but it is not always necessary. Dickie's definition allows us to apply the term 'art' also to objects that are in fact never exhibited so long as they were intended for exhibition or belong to a kind of artefact that is usually exhibited (e.g. paintings). It should moreover be noted that Dickie doesn't intend the words 'artifact' and 'created' to be taken in their ordinary sense. In the first version of his theory, Dickie was prepared to say that a piece of wood or a pebble could become an artifact by someone's 'conferring artifactuality' on it. In the later version he withdrew this paradoxical formulation, but continued to allow 
for 'artifacts' that are not actually artificially produced or man-made: Through the mere act of presentation a pebble is transformed into the 'complex object': 'the-pebble-used-as-an-artistic-medium', which Dickie is happy to regard as an 'artifact'. In other words, Dickie ignores the difference between creation and presentation. ${ }^{2}$

What Dickie purports to define is 'a work of art in the classificatory sense', which means that his concern is an entirely non-evaluative concept of art. ${ }^{3}$ That is what makes his definition so provocative: its implicit claim that the concept of art, in its basic and ordinary sense, carries no evaluative connotation whatsoever. For something to qualify as a work of art it need not be worthwhile or have any value; it can literally be a load of rubbish, provided it is suitably exhibited.

Not surprisingly, the claim that art is not an evaluative concept has been heavily contested. ${ }^{4}$ The opposing view that for something to count as art it must be valuable has sometimes been supported by a functional account of art. On this view, a work of art is an artefact whose principal aim or function it is to afford us aesthetic pleasure or an interesting aesthetic experience. ${ }^{5}$ This is thought to explain why at least some minimum value must be implied by the very word 'art'.

Let us first consider whether the idea of a strictly non-evaluative concept of art can be defended. Is it possible to identify something as 'art' without in any way committing oneself to a value judgement?

To begin with, we should note that it is of course possible to use the word 'art' in inverted commas (literally or figuratively) when referring to others' application of the term without endorsement. When I say, for example, with a sceptical or ironical intonation: 'This work of art costs $£_{50,000}$ ', I use the term, as it were, in inverted commas, citing others' judgement that the object in question is a work of art without acceding to it. That, however, does not involve a new meaning of the term. If 'art' is an evaluative term, then, like any other evaluative term, it can be used in this quotational manner without thereby producing a non-evaluative concept.

In his article 'Art and Value' - subsequently reprinted as the final chapter of a book of the same title $^{6}$ - Dickie tried to answer the objection that 'art' is essentially an evaluative term. He made three points:

(i) On an evaluative construal of the concept of art it is difficult to make sense of such common expressions as 'mediocre art', 'bad art' or 'good art'. The first two would appear self-contradictory, while the last one would be a pleonasm.? 
(ii) Where the term 'art' is used evaluatively it always, or at least frequently, means: 'of the greatest possible value'; ${ }^{8}$ which makes it clear that there must be another, less exalted, non-evaluative sense covering all artworks and not just rare masterpieces.

(iii) Attempts to construe the concept of art as essentially evaluative lead to the odd result that there could be two very similar objects that have to be placed into radically different categories: if one just qualifies as a work of art, while the other falls just below the value threshold required for art on such an account. ${ }^{9}$

None of these responses is convincing. I shall discuss them in turn.

Taking the last point (iii) first: There is nothing at all odd about two very similar objects falling into clearly different categories. It happens frequently where precise boundaries have been drawn. Two twin brothers may as boxers fall into different weight classes - say, one middleweight, one super welterweight - just because one of them is 10 grams heavier. Of course we are not likely to come across cases of such very similar objects falling on different sides of the art/non-art boundary. But that does not show that aesthetic value may not be an essential criterion of something's counting as art; it merely shows that no numerical scale has been laid down for aesthetic value. Unlike the IBO, the art world is not a formally organised institution with the power to stipulate precise rules and criteria for drawing and policing the boundaries of its key concepts. Therefore the concept of art and the criteria for its application must be expected to be rather vague, so that instead of a sharp cut-off point there are borderline cases about which people disagree or where they are unsure what classification to give.

On Dickie's second point (ii): He believes that, normally, 'the concept of art is not evaluative', yet, exceptionally, it can be used to express superlative praise; for example, when a theatre critic calls a play a 'work of art'. ${ }^{10}$ Following Arthur Danto, ${ }^{11}$ Dickie explains that that is because any descriptive term can be 'normativized' by being used emphatically to convey that something is a particularly fine instance of the kind in question. Thus, 'That's what I call a cup of coffee!' uses the term 'cup of coffee' in an emphatic and eulogistic way, although 'cup of coffee' is not in itself an evaluative concept.

Danto's analysis is indeed plausible: By applying a predicate with particular emphasis one can commend something as an uncommonly fine specimen of its kind. However, by saying that this cup of coffee is a particularly fine cup of coffee - or that this wall plug is a particularly fine 
wall plug - I am certainly not saying that it is an object 'of the greatest possible value'. At this point, Dickie's position appears to be somewhat inconsistent. The emphatic use of a predicate ' $F$ ' can convey that an $F$ is better than other $F s$; but how could that amount to the superlative praise that it is something 'of the greatest possible value', as according to Dickie it does in the case of 'work of art'? The obvious explanation would appear to be that the predicate 'work of art' carries some strong positive evaluation anyway. In that case it would be less surprising that by highlighting something as a particularly fine work of art one could praise it as something of the greatest possible value.

However, I don't think it's very common for critics to praise a work of art by emphatically calling it a work of art. Richard Wollheim has pointed out that in most cases where the words 'That is a work of art!' are used as emphatic praise, this is not a literal application of the term, but merely a metaphor. ${ }^{12}$ Thus one hears a painstaking and beautiful arrangement of napkins and flowers on a dinner table, or an uncommonly neat and ornamental application of icing on a birthday cake, praised as a veritable 'work of art', which is an enthusiastic approbation precisely because the achievement in question is not literally a work of art, but a much more humdrum artefact. This again might be taken to suggest that 'art' is not as neutrally descriptive a term as Dickie maintains.

Anyway, Dickie is clearly wrong to think that the evaluative use of 'art' is (always or most frequently) one of superlative praise. Where, for example, it is asked if an empty room painted in green is a work of art, or if a heap of bricks deserves to be exhibited in an art gallery, the question is not whether these objects are masterpieces, artefacts of the greatest possible value, but - much more moderately - whether they deserve any attention whatsoever: whether they merit being exhibited at all or should rather be dismissed as feeble jokes. In this familiar kind of case the word 'art' is used to express or withhold only a very moderate evaluation: for something to qualify as 'art' is for it to have a certain minimum of aesthetic value or interest.

Finally (i): Dickie makes much of the common use of expressions like 'bad art' or 'mediocre art', which he regards as evidence for his view that normally 'art' is not an evaluative term. But it is only Dickie's own peculiar and implausible construal of the evaluative sense of 'art' that comes into conflict with those locutions. Only if 'art' is taken as a term of superlative praise does it look strangely inconsistent to talk of 'mediocre art'. That in fact one does is another reason to dismiss Dickie's construal; but it does not provide any argument against a more moderately evaluative 
explication of the concept of art. If a work of art is understood as something that has a certain amount of worth or merit, or commands a certain amount of respect, then among the objects that fulfil this minimum requirement there could still be considerable differences in quality. A work of art, though never entirely without merits, can be relatively good or bad. Thus, there can be bad art just as there can be a small elephant (even though elephants are big animals). ${ }^{13}$

Dickie's arguments against the claim that art is an evaluative concept are unconvincing. But of course it doesn't follow that there could not be a neutrally descriptive concept of art all the same, coexisting perhaps with another, evaluative one championed by Dickie's critics. After all, is it not just a sociological fact - whether we like it or not - that today art can be produced by mere proclamation? Is it not true that these days anything - even utter trash - can be exhibited in a renowned art gallery and thus, as a matter of fact, be described as 'art'? Surely, if the word 'art' is commonly used in such an indiscriminate way, with no regard to the aesthetic value of the object in question, an up-to-date philosophical account has to reflect that usage. ${ }^{14}$

This argument, however, is too quick. The fact that it has become customary or fashionable in a society to apply a predicate to certain objects does not guarantee the correctness of this usage. In the middle ages, for example, it was fairly common to describe single women that appeared in some ways eccentric and had perhaps some knowledge of herbal remedies as 'witches'. It doesn't follow that those women were indeed witches, even by mediaeval standards. For the word implies, and did imply then, that the person has magical powers due to a collusion with the devil. So people were mistaken, by their own linguistic norms, in applying the term 'witch' in the way they did, even if that usage was unanimous. By the same token, it would be overly hasty to maintain that just because we have become used to applying the term 'art' to the most bizarre objects if only they are publicized in a certain way, that customary usage must be correct. It remains to be considered whether our concept of art does not have implications (manifest in other aspects of the use of the word) that would show up that customary usage as incorrect.

\section{II}

That of course is the contention of those of Dickie's critics who argue for a functional definition of art. Mark Rowe claims that the linguistic fact, pointed out by Dickie, that we speak of 'bad art' and 'mediocre art', far from supporting a non-evaluative definition, goes to show that the 
concept of art must be a functional concept, or at least associated with a function. For only insofar as we understand a work of art to be intended to fulfil a certain function can we judge it as good or bad, according to its success in fulfilling that function. ${ }^{15}$ By contrast, a word like 'crumb', not implying nor associated with any function, doesn't provide us with any criterion of assessment either. Hence, talk of 'a good crumb' or 'a bad crumb' would not be comprehensible without some further explanation. But if 'art' is acknowledged to be a functional concept - if by definition works of art fulfil a certain function: are good for something - then it follows (according to Rowe) that 'the objects which fall under the concept will have a particular kind of value.'. ${ }^{16}$

This argument seems to me open to three objections.

First: Rowe is too quick to assume that things can be judged good or bad only relative to a given aim or purpose. We speak, for example, of a good day although days are not associated with any particular function. 'Good', in such a case, may just mean 'agreeable'.

Moreover, an object has a function if it is intended to serve as a means to an end that can be specified independently of that object. But not everything we do is done in pursuit of an independently specifiable end, with respect to which it can be assessed. A handstand, for example, has, as such, no essential aim or purpose, and yet we can applaud a good handstand, which is performed smoothly and elegantly, or criticise a bad one.

Besides, even an artefact defined by its function need not be evaluated exclusively in regard to that function. ${ }^{17} \mathrm{~A}$ watch is a portable device to indicate the time of day; yet when connoisseurs value a handcrafted Swiss watch higher than a special offer at Argos that is not because the latter is less serviceable as a timepiece.

In short, the fact that works of art are judged good or bad does not show that 'art' is a functional concept. 'Good' does not always mean 'useful' or 'expedient'. 18

Second objection: Rowe maintains that a functional concept is ipso facto an evaluative concept: 'the objects which fall under the concept will have a particular kind of value',19 namely: the value that consists in their fulfilling a certain function: that they are good for something. Tin openers, for instance, are good for opening tins. In that consists their value.

That provokes the objection that not all objects falling under a functional concept do actually fulfil their function. Not all tin openers work. A broken tin opener is no good, and yet it is still a tin opener. ${ }^{20}$ Another example of a functional concept is a joke, that is, roughly speaking, an utterance (or short text, or performance) whose function is to amuse. ${ }^{21}$ 
But of course not all jokes succeed in fulfilling their function. Some jokes are not at all funny.

Or are they? At least one famous philosopher begs to differ. Donald Davidson declares in all seriousness that 'there are no unfunny jokes'. ${ }^{22}$ In other words, he wants to construe the concept of a joke as a functional success concept. And Rowe goes as far as to insist that all functional concepts must be success concepts: only what actually fulfils the function falls under the concept. Broken tin openers are strictly speaking no tin openers. ${ }^{23}$

It would appear that such a stringent construal is not in accordance with actual usage. As a matter of linguistic fact, our functional classifications go by manifest intention or purpose, rather than by actual achievement. A joke is an utterance intended to amuse, and a tin opener is a device that is meant to open tins; even though those intentions may occasionally not be fulfilled.

But Rowe offers an argument to show that such a more generous construal is mistaken: It is impossible to define a tin opener as a device intended to open tins, because

[a] tin-opener is something one can intend to make. If we take the sentence 'I intend to make [a tin-opener]' then it should be possible ... to substitute the definition for the thing defined. 'I intend to make [an object to open tins]' is perfectly intelligible, whereas 'I intend to make [an object intended to open tins]' is not - one can only make it so by ignoring 'intended'. The reason it is unintelligible is that an intention must have a goal or point. If it has a goal then there must be such a thing as achieving it or failing to achieve it. It is quite clear what failing to make an object that opens tins is, but it is not at all clear what it would be to fail in making an object intended to open tins. But if anything I do - blowing a soap bubble, making some sawdust, keeping silent - counts as success and nothing as failure then this simply shows my activity does not have a goal, and if I do not have a goal then I do not have an intention. Paradoxically, 'an object intended to open tins' cannot be the product of an intention, and as a tin-opener must be the product of an intention, this cannot be the definition of 'tin-opener'. ${ }^{24}$

The crucial step in this argument is the claim that the sentence 'I intend to make an object intended to open tins' has no clear sense since we don't know what in this case would count as success and what would count as failure. But that is false. The intention to produce an object intended to achieve a certain goal is quite understandable, as long as we have at least a rough idea of what kinds of object one could reasonably say that 
they were intended to achieve that goal. That is to say: of what kinds of object one could reasonably expect or hope that they might achieve that goal, even if perhaps they don't. Thus, for instance, I can have the intention of writing an essay intended to win a prize; for it is easy enough to distinguish the case in which at least the first intention is fulfilled (I write and submit an essay, though it may not win a prize) and the case in which it isn't (I don't even write an essay). The two occurrences of the word 'intend' (or 'intention') may not be very elegant, but they serve to emphasise that there are two distinct possibilities of failure (just as in the cautious locution 'I intend to try'). Again, using pliers, cogwheels and some other bits of metal I try to construct a mechanism intended to open tins. Even if in the end it doesn't work, I can be credited with the intention of constructing a device intended to open tins, as long as it is understandable how I thought the thing would work. If, however, I just blew a soap bubble or made some sawdust one would not be able to understand how I could possibly have expected that to work as a tin opener. Hence, in this case one could not ascribe to me the intention to make something that is meant to open tins.

Finally, there is a third objection to Rowe's attempt to prove that the term 'art' implies a positive evaluation. To repeat: he claims that art is a functional concept and that 'the objects which fall under [a functional] concept will have a particular kind of value', ${ }^{25}$ namely the value of fulfilling a certain function: of being good for something. The objection is that not everything that is good for something is good. Weapons of mass destruction are good for wreaking mass destruction. Instruments of torture are good for torturing. Granted that these things fulfil their function, one may still thoroughly disapprove of them. Something's value as a means to an end does not make it a good thing unless the end is a good thing too.

At this point it may be suggested that the end of art is clearly something good: some kind of pleasure, often combined with some intellectual stimulation. And therefore the word 'art' implies an element of commendation. However, there are many things intended to provide some kind of pleasure whose value may nonetheless be open to debate: whisky, computer games, pornography. One would hardly maintain that these concepts imply a positive evaluation. That is because the pleasure they promise is not in fact experienced by everybody - what some find enjoyable, others find boring or irritating. Moreover, one may disapprove of certain kinds of enjoyment because of their side or long-term effects or on moral grounds. Likewise, not everybody finds art enjoyable; indeed, nobody would be likely to find all art enjoyable. Most people are 
entirely indifferent to at least some art forms (just as not everybody cares for whisky), and a passionate occupation with art or literature has often been looked at askance as a frivolous waste of time.

Like 'whisky' or 'pornography', the term 'art' implies only a conditional commendation. To call something 'art' is to recommend it - to people who take an interest in art, but not to others (just as the discovery that a proffered drink is whisky is good news for some, but not for others). Pace Stanley Cavell, it is not analytically true of works of art that they are valuable. ${ }^{26}$ To regard something as art, but entirely worthless is not inconsistent. You don't even have to be a philistine to find some artistic styles fairly dull and some works of art entirely devoid of interest.

On the other hand, it is undeniable that art is generally held in high esteem in our society. Even people who personally don't take much interest in works of art tend to have a certain respect for art and artists. Artworks of the past are carefully preserved and displayed as part of our cultural heritage. Contemporary art is heavily subsidised from public funds. Artists are awarded lucrative prizes and some become famous.

The esteem that art enjoys is not, as many of Dickie's critics have suggested, part of the very meaning of the word. Yet those critics' uneasiness about Dickie's emphatically non-evaluative construal of the concept is understandable. For it is an obvious empirical fact that in most countries art has a prestige that gives the word a positive resonance (as opposed to pornography, for example, which may be just as popular, but clearly not as prestigious). In short: 'Art' is not an unconditionally evaluative concept, but it is a prestige concept.

\section{III}

If we now return to the Institutional Theory of Art we shall find that, in fact, Dickie's sociological approach to the concept of art reflects both these aspects - that although not straightforwardly evaluative, it is at least conditionally commendatory and that it is a concept conferring prestige - without, however, taking them sufficiently into account.

To repeat, Dickie's definition runs as follows:

(IT) A work of art in the classificatory sense is an artifact of a kind created to be presented to an artworld public. ${ }^{27}$

Attempting to give a sociological account of art, Dickie rightly emphasises that works of art are typically presented to an audience. ${ }^{28}$ But he seems to neglect what is worth noting, namely that the very act of presenting a work to the public amounts to an evaluative judgement by those responsible for 
the exhibition or publication. By presenting something in a gallery, one gives people to understand that one deems it worth looking at, even for a fee. ${ }^{29}$ So, even on Dickie's account, the status of being a work of art is always dependent on a positive evaluative judgement. Of course such an implicit commendation is only relative to a group of potentially interested people, roughly, those interested in (that kind of) art: 'an artworld public'. And even that group may not always share the artist's or organiser's assessment. It is, however, necessary that enough of them are in agreement with such implicit evaluative judgements fairly often. Otherwise the institutional framework that allows artists to present their work to the general public would struggle to survive.

What is so problematic about Dickie's definition (IT) is the claim that the exhibition of an object to a suitable audience turns it ipso facto into a work of art. Even if in the later version of the theory art status is no longer said to be 'conferred', the presentation that is at the heart of the new definition does amount to a proclamation. By being presented to an artworld public an object is in effect proclaimed to be a 'work of art'. Yet such a proclamation raises the question of its point. As Wittgenstein puts it: '[A game] does not just have rules; it has a point. ${ }^{30}$ If the rules of the game lay down the procedures by which something can be given a certain title, say, the title 'blig', the question arises why one should want to confer this title. What is the point of calling something 'blig'? Likewise in the case of Dickie's definition (IT): He tells us how an object - any object - could be proclaimed to be 'art', but he doesn't tell us what the point of this procedure is supposed to be. - No wonder. We all know what the point is. We wouldn't know why anyone should care to call anything 'blig', but we know perfectly well why, for example, Tracey Emin or Damien Hirst set great store by having their artefacts called 'art': they do so because 'art' expresses a concept which carries prestige in our society, it is an honorific title.

In other words, Dickie's bold claim that any object can be proclaimed to be a work of art presupposes a characteristic of the concept of art that Dickie, with his talk of a purely classificatory concept, is at pains to play down: namely, that it is generally regarded as an honour to have created a work of art. That is to say, art is a prestige concept.

This is where the tension in Dickie's theory lies, where his position turns out to be unstable. The point of such a proclamation presupposes that art has a prestige that could never be earned by proclamation. The reason why artists have traditionally been admired - even by those who are not particularly interested in their works - is that those works show 
exceptional skills. ${ }^{31}$ Dickie's theory puts an end to that. If these days art can be produced by mere proclamation, exceptional skills are no longer required in an artist. But this model of art-by-proclamation is essentially parasitic: It works only as long as more traditional ideas of art are still prevalent and able to bestow on art the prestige that makes it desirable to be regarded as an artist. Once the new model of art-by-proclamation has become fully accepted and conventional, the concept of art is likely to lose the prestige without which such a proclamation would be pointless. There are already indications that the contemporary art world, by the procedures Dickie describes, is beginning to impair art's traditional prestige. ${ }^{32}$

Thus, looked at more closely, Dickie's Definition (IT) does after all involve some reference to evaluative elements, in spite of Dickie's insistence on a purely classificatory concept. The act of exhibiting something amounts to the claim that the object is worthwhile; and the idea that merely by being (created to be) exhibited an object can gain the title of a work of art presupposes the prestige enjoyed by that concept. At least the former aspect might usefully be made explicit in the definition, and that may, to some extent, also serve to allay concerns about the second:

(IT1) A work of art is an artifact of a kind created and regarded as worthy to be presented to an artworld public.

But even this revision will not suffice to meet the concern that the Institutional Theory is too inclusive. After all, one can easily imagine that even for the most nugatory object there will be some attention-seeking eccentric to champion it as worthwhile. That is the reason why Rowe tried to show good intentions to be insufficient, insisting on a minimum of actual aesthetic quality; yet his argument proved unconvincing. If 'art' is a functional concept (as Rowe maintains) one should expect, by analogy with other functional concepts, that not all works of art succeed in fulfilling art's function (just as not all tin openers work and not all jokes are actually funny). One would, however, be entitled to insist that the objects in question be not too obviously defective. ${ }^{33}$

A joke need not be funny in order to qualify as a joke; but it must be understandable how a moderately sensible person could at least expect it to be funny. Let us revise (IT1) accordingly:

(IT2) A work of art is an artifact of a kind created and regarded as worthy to be presented to an artworld public. And the judgement that the object deserves the artworld's attention must not be too unreasonable. 
This revised definition is superior to Dickie's original in that it leaves the question as to whether something is art appropriately open. For people do disagree fairly frequently whether exhibits in modern art galleries deserve to be called 'art'. The Institutional Theory stipulates that in any case where the question arises the answer must be Yes. Those who disagree would on Dickie's account be talking nonsense (by making the patently inconsistent claim that what was evidently an artefact created to be presented to an artworld public was not such an artefact), whereas in fact it is clear that they are not: They may be narrow-minded, lacking in openness towards artistic originality, but their mistake is not simply a linguistic or logical one. Hence Dickie's definition founders at the linguistic facts it is supposed to account for.

Admittedly, even the revised version (IT2) is not a proper definition of a work of art, since, due to its reference to the artworld, it is hopelessly circular. But it might at least serve as a partial elucidation of the concept.

\section{IV}

Aesthetic functionalists would agree that works of art are typically exhibited to an artworld public, but do not regard that as a defining feature. Rather, they try to define a work of art as an artefact whose principal function it is to produce worthwhile aesthetic experiences in the audience (spectator, listener, or reader). ${ }^{34}$ Is that correct? Is 'art' a functional concept? As argued above, aesthetic functionalism cannot simply be derived from the fact that works of art are judged to be good or bad. 'Good' or 'bad' need not mean: good or bad in fulfilling a given function.

It is undeniable that works of art can afford us valuable aesthetic experiences, and of course, that is not a coincidence: they are supposed to do so. So why not say: that is their purpose, use or function?

Contrary to this idea, there has been a long tradition in aesthetics asserting that an essential characteristic of works of art is their uselessness. ${ }^{35}$ The purpose of a tin opener is to open tins; a car is used to convey us fast and conveniently from one place to another; an aspirin serves to alleviate pains; and what is the use of a work of art? On this view, it has no purpose. Unlike a tin opener, a car or an aspirin, it is not to be regarded as a means to an end. Rather, a work of art is appreciated for its own sake. That is not to deny that works of art can be, and often are, used as means to an end: as a source of information, as political propaganda, as a status symbol, or as an investment. But such uses are alien to art. Using a work of art in one of those ways is not to use it as a work of art.

There are other things that can be valued either as means to an end or 
for their own sake. A walk, for example, can serve the purpose of keeping in good health, or to familiarise oneself with the area, or as a convenient setting for a confidential conversation. But some people just enjoy walking with no such end in view. For them going for a walk is an end in itself.

One might respond, however, that even such a person values a walk as a means to an end, namely as a means to certain agreeable experiences. And likewise, aesthetic functionalists hold that when we say that we value a work of art for its own sake, that is just a different way of saying that we value the aesthetic experiences that it can afford us.

Undeniably, when we appreciate a work of art we value it as a source of aesthetic experiences. But it would be rash therefore to regard works of art as means to an end. For that would suggest that one uses or employs a work of art in order to achieve an effect that is logically independent of that application. In that way, one applies a tin opener, thus causing a tin to be open; and one uses, swallows, a tablet hoping thus to cause one's headache to go away. Yet there is no such distinction between applying a means and achieving an end in the case of the appreciation of art. Looking at a picture or listening to music does not cause an aesthetic experience, it is an aesthetic experience. ${ }^{36}$

Moreover, what is merely a means to an end is, at least in principle, replaceable without loss by other means to obtain the same end. Thus, if a work of art were regarded as a means to procuring aesthetic experiences, it should be easily replaceable by other works of art of comparable efficacy; just as one good tin opener can without loss be replaced by another. But in fact, our attitude towards works of art is rarely that promiscuous. ${ }^{37}$ Somebody going to see an exhibition of Dutch still lifes will hardly be content to be shown a ballet instead, or a volume of sonnets, even if they have equally good claims to being enjoyable. That would be like asking for a tin opener and being given a waffle iron; both are useful kitchen appliances, no doubt, but accommodating very different culinary interests. The concept of aesthetic experience is far less specific than most people's aesthetic interests most of the time. Hence, to say of a work of art that it is supposed to afford us aesthetic experiences is rather like saying of a tin opener that it is to be useful in the kitchen. True, but not a specification of the object's function.

Not only are the aesthetic experiences produced in us by a painting not equivalent to those produced by a play or a poem; they are also crucially different from those produced by other paintings. Works of art are essentially individual objects whose value lies in their individual characteristics. ${ }^{38}$ That is what distinguishes them from functionally defined 
objects, such as tin openers or cars. The aesthetic experience of listening to a performance of Mozart's Requiem is largely determined by the specific characteristics of (the performance of) the piece of music that is its intentional object. A description of my aesthetic experience would be a description of Mozart's Requiem, or a particular production of it, as I perceived it. And this is obviously an experience that could not be produced by any other work (unless my perception was so careless and unschooled that I could not tell the two apart). Therefore, provided that an aesthetic experience of a work of art is appropriately discerning, it is impossible to separate it from the work of art, as if it were the work's aim and logically independent of it. ${ }^{39}$ The link between work and experience is not just causal (like that between aspirin and the removal of a headache), but conceptual: One cannot take an interest in the latter without ipso facto being interested in the former. Therefore, the truism that our interest in works of art is due to an interest in the aesthetic experiences they promise to afford us is not an objection to the view that we are interested in works of art for their own sake. For the aesthetic experience is essentially an aesthetic experience of the work itself. So, the value of a work of art cannot usefully be explained as its function to produce certain effects. The analogy with functional concepts (such as cars or tin openers) is ultimately misleading.

\section{Notes}

1. George Dickie, 'Art and Value', British Journal of Aesthetics 40 (2000), 228-41; 228.

2. Dickie is likely to brush aside criticism of this cavalier use of words with the contention that his concern is metaphysics, not philosophy of language. See The Art Circle: A Theory of Art (New York: Haven, 1984), 13 and 37; cf. Lauren Tillinghast, 'The Classificatory Sense of "Art", Journal of Aesthetics and Art Criticism 61:2 (2003), 133-48; 143-44). It would appear that metaphysics is a discipline in which verbal accuracy is less important than in other branches of philosophy.

3. Dickie, 'Art and Value', 239.

4. E.g. S. Cavell, 'A Matter of Meaning It', in his: Must We Mean What We Say? (Cambridge: Cambridge University Press, 1976), 13-37; 216: 'that works of art are valuable is analytically true of them'. M. W. Rowe, 'Why "Art" doesn't have Two Senses', British Journal of Aesthetics 31:3 (1991), 214-21; 217: 'objects which fall under the concept [of art] will have a particular kind of value'. S. Gardner, 'Aesthetics', in The Blackwell Companion to Philosophy (Oxford: Blackwell, 1996), eds. N. Bunnin and E. Tsui-James, 229-56; 236: 'it is simply a mistake to separate 
the classificatory sense of art from the evaluative. Evaluation is just as integral to the concept of art as it is to moral concepts'. B. Tilghman, 'Review of A. Goldman's Aesthetic Value', Journal of Aesthetics and Art Criticism 57:1 (1999), p. 81: 'Our ordinary concept of art ... is evaluative'.

5. Rowe, ibid. Other proponents of a functional account of art are: M. Beardsley (Aesthetics: Problems in the Philosophy of Criticism, Indianapolis: Hackett, 1981; \28); R. Kamber ('A Modest Proposal for Defining a Work of Art', British Journal of Aesthetics 33:4 (1993), 313-20); G. Oppy ('On Functional Definitions of Art: A Response to Rowe', British Journal of Aesthetics 33:1 (1993), 67-71); O. Hanfling ('Art, Artifact and Function', Philosophical Investigations 18:1 (1995), 1-48); R. Stecker (Artworks: Definition, Meaning, Value, Philadelphia: Pennsylvania State University Press, 1997); R. Scruton ('In Search of the Aesthetic', British Journal of Aesthetics 47:3 (2007), 232-50).

6. Dickie, Art and Value, Oxford: Blackwell, 2001.

7. Dickie, 'Art and Value', 230, 235.

8. Ibid., 233.

9. Ibid.

10. Ibid., 239, 236.

11. A. Danto, 'Art and Meaning', in Theories of Art Today, ed. N. Carroll (Madison: The University of Wisconsin Press, 2000), 130-40.

12. R. Wollheim, 'The Institutional theory of art', in Art and its Objects, second edition (Cambridge: Cambridge University Press, 1980), 157-66; 159.

13. This is, for example, Mark Rowe's view: 'Not all art is good art, but the application of the concept implies that a certain minimal standard has been achieved' (Rowe, ibid., 218). Similarly, Stephen Davies: 'There is a threshold of merit ... which a work must meet before it qualifies as an artwork', Definitions of Art (Ithaca NY: Cornell UP, 1991), 42.

14. D. Matravers, 'Institutional Definitions and Reasons', British Journal of Aesthetics 47:3 (2007), 251-57; 253-54.

15. Rowe, ibid., 216.

16. Rowe, ibid., 217.

17. Cf. Oppy, 'On Functional Definitions of Art: A Response to Rowe', 68.

18. In the following considerations I shall, however, assume for argument's sake that 'art' is a functional concept, postponing a critical discussion of this view till the final part of the paper.

19. Rowe, ibid., p.217.

20. Oppy, ibid., 68; Hanfling, ibid., 40, note 11; Matravers, ibid., 253.

21. I am not concerned here with a precise definition of a joke, distinguishing it from other humorous genres, such as witticism, comedy sketch, limerick, or comic song. 
22. D. Davidson, 'What Metaphors Mean', in his Inquiries into Truth \& Interpretation, (Oxford: Blackwell, 1984), 245-64; 245.

23. Rowe, ibid., 215.

24. Ibid., $215^{-16 .}$

25. Ibid., 217.

26. Cavell, ibid., 216.

27. Dickie, 'Art and Value', 228.

28. Cf. D. Dutton, 'A Naturalist Definition of Art', Journal of Aesthetics and Art Criticism 64:3 (2006), 367-77; 371: \$7.

29. That is also implied by Dickie's observation that occasionally artists hold back their works 'because they judge them unworthy of presentation', see his Introduction to Aesthetics: An Analytic Approach (New York: Oxford University Press, 1997), 89. And it is even more obvious in an older version of Dickie's Institutional Theory, which has it that an artefact becomes a work of art by being put forward as a 'candidate for appreciation', that is, as something proposed to be worthy of appreciation (ibid., 83-84).

30. Wittgenstein, Remarks on the Foundations of Mathematics, eds. G. H. von Wright, R. Rhees, G. E. M. Anscombe, trans. G.E.M. Anscombe, rev. ed. (Oxford: Blackwell, 1978), 109.

31. Cf. Dutton, ibid., 369-70: $\$ 2$.

32. Cf. J. Carey, What good are the arts? (London: Faber \& Faber, 2005).

33. Thus I am inclined to agree with Rowe when he wants to exclude from the domain of art objects 'where we cannot begin to understand how the maker or arranger hoped to hold the attention of his audience' (Rowe, ibid., 219).

34. Dickie, on the other hand, agrees that art has that function, but doesn't regard it as a defining characteristic (Introduction to Aesthetics, 157ff.).

35. Cf. P. Lamarque, 'The Uselessness of Art', Journal of Aesthetics and Art Criticism 68:3 (2010), 205-14.

36. It is arguable that in some cases, especially with longer narrative art forms, the aesthetic experience lasts much longer than the actual perception or perusal of the work of art (cf. P. Kivy, The Performance of Reading, Oxford: Blackwell, 2006), but even then the latter is clearly the core and most intensive part of that experience.

37. Cf. Wittgenstein, Lectures \& Conversations on Aesthetics, Psychology and Religious Belief, ed. C. Barrett (Oxford: Blackwell, 1978), 29 and 34.

38. Cf. P. F. Strawson, 'Aesthetics Appraisal and Works of Art', in his Freedom and Resentment and Other Essays (London: Methuen, 1974), 178-88.

39. Cf. M. Budd, Values of Art (London: Allen Lane, 1995), 4. 